\title{
Sciatic nerve and its variations: is it possible to associate them with piriformis syndrome?
}

\author{
Nervo isquiático e suas variações: é possível associá-las à síndrome do piriforme? \\ Ana Beatriz Marques BARBOSAㄱ, Priscele Viana dos SANTOS ${ }^{1}$, Vanessa Apolonio TARGINO', Nathalie de \\ Almeida SILVA², Yanka Costa de Melo SILVA², Felippe Barbosa GOMES ${ }^{3}$, Thiago de Oliveira ASSIS $3,4,5$
}

\begin{abstract}
The sciatic nerve forms from the roots of the lumbosacral plexus and emerges from the pelvis passing inferiorly to the piriformis muscle, towards the lower limb where it divides into common tibial and fibular nerves. Anatomical variations related to the area where the nerve divides, as well as its path, seem to be factors related to piriformis syndrome. Objective: To analyze the anatomical variations of the sciatic nerve and its clinical implications. Methods: This was a systematic review of articles indexed in the PubMed, LILACS, SciELO, SpringerLink, ScienceDirect and Latindex databases from August to September 2018. Original articles covering variations of the sciatic nerve were included. The level of the sciatic nerve division and its path in relation to the piriformis muscle was considered for this study. The collection was performed by two independent reviewers. Results: At the end of the search, 12 articles were selected, characterized according to the sample, method of evaluation of the anatomical structure and the main results. The most prevalent anatomical variation was that the common fibular nerve passed through the piriformis muscle fibers (33.3\%). Three studies (25\%) also observed anatomical variations not classified in the literature and, in three (25\%) the presence of a double piriformis muscle was found. Conclusion: The results of this review showed the most prevalent variations of the sciatic nerve and point to a possible association of this condition with piriformis syndrome. Therefore, these variations should be considered during the semiology of disorders involving parts of the lower limbs.
\end{abstract}

Keywords: Piriformis muscle; sciatic nerve; anatomy

\section{RESUMO}

O nervo isquiático forma-se a partir das raízes do plexo lombosacro e emerge da pelve passando inferiormente ao músculo piriforme, em direção ao membro inferior onde se divide em nervos tibial e fibular comum. Variações anatômicas relativas ao local onde ocorre a divisão desse nervo, bem como do seu trajeto, parecem ser fatores relacionados à síndrome do piriforme. Objetivo: Analisar as variações anatômicas do nervo isquiático e suas implicações clínicas. Materiais e Métodos: Trata-se de uma revisão sistemática de artigos indexados nas bases de dados PubMed, LILACS, SciELO, SPRINGERLINK, SCIENC DIRECT e LATINDEX. Foram incluídos artigos originais envolvendo as variações do nervo isquiático. Considerou-se para este estudo o nível de divisão do nervo isquiático e o seu trajeto em relação ao músculo piriforme. A coleta foi realizada por dois revisores independentes. Resultados: Ao final da busca foram selecionados 12 artigos, caracterizados quanto à amostra, método para avaliar a estrutura anatômica e principais resultados. A variação anatômica mais prevalente foi aquela em que o nervo fibular comum atravessa as fibras do músculo piriforme (33,3\%). Três estudos (25\%) observaram, ainda, variações anatômicas não classificadas na literatura e em outros três (25\%) constatou-se a presença de um músculo piriforme duplo. Conclusão: Os resultados desta revisão mostram as variações mais prevalentes do nervo isquiático e apontam para uma possível associação dessa condição com a síndrome do piriforme. Desse modo, essas variações devem ser consideradas durante a semiologia dos distúrbios envolvendo os membros inferiores.

Palavras-chave: Músculo piriforme; nervo ciático; anatomia

${ }^{1}$ Centro Universitário UNIFACISA, Curso de Fisioterapia, Campina Grande PB, Brasil;

${ }^{2}$ Centro Universitário UNIFACISA, Curso de Medicina, Campina Grande PB, Brasil;

${ }^{3}$ Centro Universitário UNIFACISA, Campina Grande PB, Brasil;

¿Universidade Federal da Paraíba, Departamento de Morfologia, João Pessoa PB, Brasil;

${ }^{5}$ Universidade Estadual da Paraíba, Departamento de Biologia, Campina Grande PB, Brasil.

Ana Beatriz Marques Barbosa (iD) https://orcid.org/0000-0002-5427-8476; Priscele Viana dos Santos (iD) https://orcid.org/0000-0001-7325-5635; Vanessa Apolonio Targino (ID https://orcid.org/0000-0002-0270-447X; Nathalie de Almeida Silva (ID) https://orcid.org/0000-0002-9707-9661; Yanka Costa de Melo Silva (iD https://orcid.org/0000-0002-4901-0096; Felippe Barbosa Gomes iD https://orcid.org/0000-0002-2342-9614; Thiago de Oliveira Assis (iD) https://orcid.org/0000-0001-8725-0456

Correspondence: Thiago de Oliveira Assis; Departamento de Biologia / UEPB; Rua Domitila Cabral de Castro, s/n - Universitário, Campina Grande - PB, 58429-600 Campina Grande PB, Brasil; E-mail: thiago.oa@hotmail.com

Conflict of interest: There is no conflict of interest to declare.

Received 25 February 2019; Received in final form 21 April 2019; Accepted 05 May 2019. 
The sciatic nerve is the largest and most bulky nerve in the human body, about $2 \mathrm{~cm}$ wide and $0.5 \mathrm{~cm}$ thick at its origin, near the lumbosacral plexus ${ }^{1}$. This nerve forms from the roots of the L4-S3 segments of the lumbosacral plexus, traversing the lower limb, from its origin in the posterior hip to the hallux. It is responsible for the innervation of the posterior leg compartment muscles (hamstrings), the muscles of all leg compartments and both sides of the foot and is, therefore, the lower limbs' main nerve. It is also responsible for cutaneous innervation of the leg and foot, except in its medial regions ${ }^{2}$.

This nerve, in normal anatomy, emerges from the posterior area of the pelvic girdle, through the large sciatic foramen, passing inferiorly to the piriformis muscle (infrapiriform area). It follows a descending path along the thigh up to the proximal region of the popliteal fossa, where it divides into its terminal branches, the tibial nerve and the common fibular nerve ${ }^{1}$. Although this is the typical anatomical pattern, variations related to the location where the nerve divides, as well as its path in relation to the piriformis muscle, have been observed ${ }^{3}$.

In a study performed on Caucasian cadavers (294 members), the normal pattern was observed in $93.6 \%$ of the dissected limbs. Among the variations found, the sciatic nerve exiting the pelvis from the suprapiriform area $(0.3 \%)$ and between its fibers $(0.3 \%)$ was observed. In one of the dissected pieces, the sciatic nerve was divided at the piriformis muscle level and each of its branches assumed opposite paths, one leaving the supra-pectoral area and the other through the infrapiriform area ${ }^{4}$.

The topographic anatomy variations of the sciatic nerve and the piriformis muscle seem to be related to the development of important clinical conditions, such as piriformis syndrome ${ }^{4}$. This is a rare condition characterized by the presence of pain in the gluteal and lumbar region that may or may not radiate to the lower ipsilateral limb 5 . One of the mechanisms involved in the development of this condition is due to the compression or irritation of the sciatic nerve as it passes through the piriformis muscle 6 . The inflamed, spastic or elongated muscle compresses the nerve between the muscle tendon and the bony pelvis, generating the typical pain picture often clinically confused with a herniated disc ${ }^{7}$.

In this context, a reduction of the space through which the sciatic nerve leaves the pelvis, as in the anatomical variations of its path and division, could cause its entrapment or compression, leading to a neuropathy characteristic of piriformis syndrome. The deep gluteal region is of great clinical importance due to the location of anatomical structures in this area and their relationship with the piriformis muscle, which can often result in pain and paresis of the affected limb, characteristic symptoms of the syndrome. Additionally, sciatica may also be accompanied by changes in the biomechanics of the pelvic girdle, leading to physical incapacity for locomotion and reduction of the patient's quality of life ${ }^{8}$.

Given this scenario, it is necessary to understand the variant anatomy of the sciatic nerve and its passage through the sciatic foramen in order to identify an association between the symptoms reported by the patients with their anatomy, increasing the sensitivity of the differential diagnosis and consequently leading to more effective treatment. In this context, this study analyzed the anatomical variations of the sciatic nerve and their relation to piriformis syndrome.

\section{METHODS}

This was a systematic review. For the accomplishment of this study the following databases were consulted: SciELO; PUBMED; LILACS; SpringerLink, ScienceDirect and Latindex. The electronic search was carried out from August to September 2018. Articles were selected without time restriction, in English and Portuguese languages. For the data mining of the studies the descriptors were used in combination with boolean operators (AND). In SciELO, PUBMED and ScienceDirect, the combination considered was "anatomical variation" AND "piriformis syndrome”. In LILACS, SpringerLink and Latindex "anatomical variation” AND "piriformis syndrome" AND "sciatic nerve".

For the calculation of the total number of studies, we verified that the studies were not duplicated, and each article was considered only once. From the identified studies, those that fulfilled the inclusion criteria were selected based on the initial reading of the titles and abstracts.

Original, imaging records or human cadaver articles were included, involving the anatomical variations of the sciatic nerve in relation to the piriformis muscle. We excluded review articles, studies with animal models and those reporting on piriformis syndrome unrelated to anatomical variations of the sciatic nerve.

The search was performed, independently, by two reviewers. The interobserver agreement analysis was performed using the Kappa test (BioEstat V 5.0), according to the Landis and $\mathrm{Koch}^{9}$ method. The $\mathrm{K}$ value found was 0.78 (which reflected substantial agreement).

The articles were critically analyzed through an interpretation guide, used to evaluate their individual quality, based on studies by Greehalgh ${ }^{10}$ and adapted by MacDermid et al. ${ }^{11}$. The articles' quality evaluation items are expressed by scores in Table 1, in which $0=$ absent; 1 = incomplete; and 2 = complete. The calculation of the percentage in Table 1 was performed by the sum of the points reached in each evaluation criterion divided by the maximum expected in each item. The follow-up criterion described in item 6 was not applicable to this study. 
Table 1. Analysis of the quality of the articles evaluating the relationship between anatomical variations of the sciatic nerve and piriformis syndrome.

\begin{tabular}{|c|c|c|c|c|c|c|c|c|c|c|c|c|c|}
\hline \multirow{2}{*}{ Studies } & \multicolumn{13}{|c|}{ Evaluation criteria } \\
\hline & 1 & 2 & 3 & 4 & 5 & 6 & 7 & 8 & 9 & 10 & 11 & 12 & Total (\%) \\
\hline Ugrenovic et al. (2005) ${ }^{21}$ & 2 & 1 & 2 & 2 & 2 & NA & 2 & 1 & 2 & 2 & 0 & 1 & 77.27 \\
\hline Pokorný et al. (2006) ${ }^{18}$ & 1 & 1 & 2 & 0 & 2 & NA & 1 & 0 & 1 & 2 & 0 & 1 & 50.00 \\
\hline Polesello et al. (2013) ${ }^{19}$ & 1 & 1 & 2 & 0 & 1 & NA & 2 & 0 & 2 & 2 & 0 & 2 & 59.09 \\
\hline Gomes et al. $(2014)^{14}$ & 2 & 0 & 2 & 2 & 1 & NA & 2 & 2 & 2 & 2 & 0 & 1 & 72.72 \\
\hline Jacomo et al. $(2014)^{15}$ & 1 & 0 & 2 & 2 & 1 & NA & 2 & 0 & 1 & 2 & 0 & 1 & 54.54 \\
\hline Natsis et al. $(2014)^{4}$ & 2 & 1 & 2 & 2 & 2 & NA & 1 & 1 & 2 & 2 & 0 & 2 & 77.27 \\
\hline Sulak et al. $(2014)^{20}$ & 2 & 2 & 1 & 2 & 2 & NA & 2 & 2 & 2 & 2 & 0 & 1 & 81.81 \\
\hline Berihu e Debeb (2015) ${ }^{12}$ & 2 & 2 & 1 & 0 & 2 & NA & 2 & 0 & 2 & 2 & 0 & 1 & 63.63 \\
\hline Kabakci et al. (2016) ${ }^{16}$ & 2 & 2 & 2 & 2 & 2 & NA & 2 & 2 & 2 & 2 & 0 & 1 & 86.36 \\
\hline Lewis et al. (2016) ${ }^{17}$ & 2 & 1 & 1 & 0 & 2 & NA & 2 & 0 & 0 & 2 & 0 & 1 & 50.00 \\
\hline Carnevalli et al. (2017) ${ }^{13}$ & 2 & 1 & 1 & 0 & 2 & NA & 1 & 0 & 1 & 2 & 0 & 1 & 50.00 \\
\hline Varenika et al. (2017) 22 & 2 & 1 & 2 & 2 & 2 & NA & 2 & 2 & 2 & 2 & 0 & 1 & 81.81 \\
\hline
\end{tabular}

Evaluation criteria - 1: thorough review of the literature to define the research question; 2: specific inclusion/exclusion criteria; 3 : specific assumptions; 4: appropriate scope of psychometric properties; 5 : sample size; 6: follow-up (not relevant for this study); 7: the authors referred to specific procedures for administration, execution and interpretation of procedures; 8: measurement techniques were standardized; 9: data were presented for each hypothesis; 10: appropriate statistics - timely estimates; 11: appropriate statistical error estimates; 12: valid conclusions and clinical recommendations.

Scoring: 0 = absent; 1 = incomplete; 2 = complete; NA: not applicable.

\section{RESULTS}

A summary of the electronic search in the selected databases is presented in Figure 1. Initially, 185 articles were identified, of which 142 were excluded, 65 of which were not relevant, such as descriptions of anatomical variations in the sciatic nerve and 77 because they were duplicates; the remaining 43 were submitted for analysis and verification of the titles and abstracts according to the inclusion and exclusion criteria. Of these, all 43 were read in full, of which only 12 articles $4,12,13,14,15,16,17,18,19,20,21,22$ adequately met all the inclusion criteria and were, therefore, selected for this integrative review in Table 2.

The classification of the normal (most common) anatomy of the sciatic nerve and its path in relation to the piriformis muscle is illustrated as Type 1 in Figure 2. The other illustrations (Type 2 to Type 13) represent the anatomical variations found.

We found 13 different sciatic nerve anatomies, of which 12 were variations. In Figure 2, the major sciatic foramen and its elements are schematically represented to better illustrate these variations. Type 1 - shows the sciatic nerve emerging as a single trunk and leaving the pelvis at the infrapiriform area (normal pattern); Type 2 - when the sciatic nerve emerges as a single trunk coming out of the pelvis through the suprapiriform area; Type 3 - when it leaves the pelvis with its terminal roots in a way that the common fibular nerve passes through the fibers of the piriformis muscle; Type 4 - when the common fibular nerve passes through the suprapiriform area and the tibial nerve through the infrapiriform area; Type 5 - when there is a high bifurcation of the tibial nerve; Type 6 - when a sciatic nerve trifurcation occurs in the infrapiriform area into the tibial nerve, abnormal trunk and common fibular branch; Type 7 - when the sciatic nerve emerges divided and the common fibular nerve passes between the heads of a double piriformis, while the tibial nerve passed beneath the muscle; Type 8 - when the common fibular nerve passes over the muscle and then joins with the tibial nerve that passed beneath the muscle; Type 9 - when the tibial nerve and common fibular nerve pass between the superficial and deep ventricles of the piriformis and then join; Type 10 - when the sciatic nerve divides and both divisions pass above the piriformis; Type 11 - when the piriformis muscle has three muscular bellies and the common fibular nerve passes between the superficial and intermediate belly and the tibial nerve passes over the deep belly; Type 12 - when both root terminals of the sciatic nerve pass through the ventricles of the piriformis; Type 13 - when the sciatic nerve exits the pelvis through the smaller sciatic foramen.

Ten of the twelve articles included in this review used the cadaveric dissection method to analyze variations in the sciatic nerve anatomy in relation to the piriformis muscle $e^{411-18,20,21}$, while the other two used radiological methods ${ }^{19,22}$. In nine (75\%) of the selected articles, type 1 anatomical variations were observed, which corresponds to the normal anatomical pattern ${ }^{4,12-14,17,18,20,21,22}$, five (41.67\%) authors found type 3 variation ${ }^{13,14,17,19,22}$, three (25\%) type $4^{4,17,22}$ and one (8.33\%) type $2^{13}$.

Also, unclassified alterations were reported in three (25\%) of the studies, referring to the sciatic nerve division level ${ }^{15,16,21}$ and another three (25\%) found the presence of a 


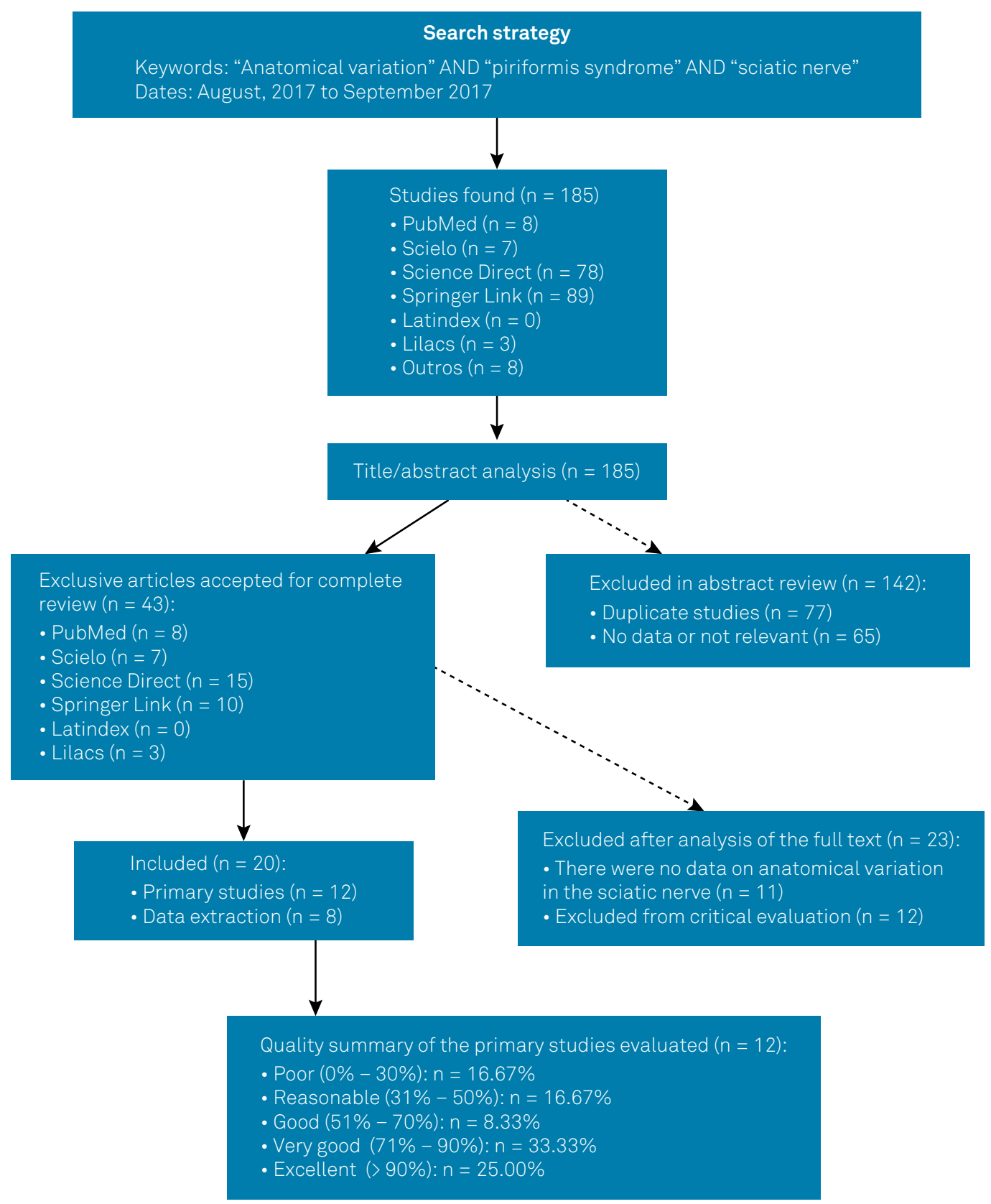

Figure 1. Studies included and excluded in the review on anatomical variations of the sciatic nerve related to piriformis syndrome.

double piriformis ${ }^{4,15,19}$. In addition, three studies were performed on human fetal cadaveric specimens at different gestational periods, where variations of type 5 and 13 could be associated with the onset of piriformis syndrome ${ }^{16,20,21}$.

The most prevalent atypical anatomical variation in this review was type 3, which showed the sciatic nerve forming its terminal roots while still inside the pelvis and its common fibular root exiting through the piriformis muscle fibers.

\section{DISCUSSION}

The relationship between the sciatic nerve and the piriformis syndrome has been found in the scientific literature and, in some cases, a direct connection of this syndrome with some of its anatomical variations has been verified. However, it cannot always be said that these changes are associated with the etiology and are responsible for pain, as asymptomatic patients may have the variations, but symptomatic patients may not present with these variations ${ }^{23}$.

We believe that the different forms of passage of the sciatic nerve through the piriformis muscle fibers generate ischemic compression and are capable of reproducing symptoms related to the dermatomes and myotomes of the competence of these nerve roots.

Yet, the data presented in this review show that anatomical variation of the sciatic nerve is not an uncommon condition. A study of 100 human fetal cadaveric specimens found 
Table 2. Summary of the selected studies which analyze the relationship between the sciatic nerve anatomical variations and piriformis syndrome.

\begin{tabular}{|c|c|c|c|}
\hline Author (year) & Sample & Methods & Main results \\
\hline Berihu; Debeb (2015) ${ }^{12}$ & $\begin{array}{c}28 \text { corpses } \\
\text { (56 lower limbs) }\end{array}$ & Corpse dissection & $\begin{array}{c}75 \% \text { of the limbs showed normal anatomy of the sciatic nerve. } \\
\text { Of the } 25 \% \text { that showed variations, } 11 \% \text { were related to the } \\
\text { piriformis muscle, } 5 \% \text { to the trifurcation of the sciatic nerve and } \\
9 \% \text { to the variation in the sural nerve origin }\end{array}$ \\
\hline Carnevalli, et al. (2017) & $\begin{array}{l}104 \text { gluteal } \\
\text { regions of adult } \\
\text { cadavers, of both } \\
\text { sexes }\end{array}$ & Corpse dissection & $\begin{array}{c}\text { In } 87.5 \% \text { the sciatic nerve emerges undivided and passes under } \\
\text { the piriformis muscle; in } 11.54 \% \text { the sciatic nerve emerges } \\
\text { divided, and the common fibular nerve traverses the piriformis } \\
\text { muscle, and in } 0.96 \% \text { the sciatic nerve exists as the single trunk } \\
\text { through the suprapiriform area. }\end{array}$ \\
\hline
\end{tabular}

20 corpses,
Gomes, et al. $(2014)^{14} \quad \begin{gathered}17 \text { males and } \\ 3 \text { females }\end{gathered}$

One Caucasian
Jacomo, et al. $(2014)^{15} \quad \begin{gathered}\text { of } 58 \text { years } \\ \text { of age }\end{gathered}$

60 fetuses

Kabakci, et al. (2016) $\quad$ (9 and 40 weeks of $\quad$ Corpse dissection gestation)

$\begin{array}{cc} & 51 \text { corpses } \\ \text { Lewis, et al. }(2016)^{17} & (102 \text { lower limbs })\end{array}$

Natsis, et al. (2014)

147 Caucasian
corpses (294 lower Corpse dissection
limbs)

$\begin{array}{lcc}\text { Pokorný, et al }(2006)^{18} & 91 \text { corpses } & \\ \text { Polesello, et al. }(2013)^{19} & \begin{array}{c}\text { One female } \\ \text { patient, 42 years } \\ \text { old }\end{array} & \begin{array}{c}\text { Magnetic resonance } \\ \text { imaging }\end{array}\end{array}$

Sulak, et al. (2014) $\quad \begin{array}{ll}20 \text { sciatic nerves } & \text { in human fetuses }\end{array} \quad$ Corpse dissection

$\begin{array}{cc} & 100 \text { human } \\ \text { Ugrenovic, et al. }(2005)^{21} \quad \begin{array}{l}\text { fetuses in various } \\ \text { gestational } \\ \text { periods and for } \\ \text { both sexes }\end{array}\end{array}$

Varenika, et al. (2017) $22 \quad 755$ exams $\begin{gathered}\text { Magnetic resonance } \\ \text { imaging }\end{gathered}$

17 corpses had a normal branching pattern, ie, the nerve emerged undivided and passed beneath the piriformis muscle. In $12.5 \%$, the fibular nerve passed inside the belly of piriformis muscle. One cadaver presented with an anatomical variation type 3 in the left hip and type 1 in the right

The cadaver showed high division of the sciatic nerve and the presence of an accessory piriformis muscle. The sciatic nerve was divided under the piriformis muscle, whereas the tibial nerve reflected anteriorly to pass between the accessory piriformis and the superior gemellus muscle

In $82.5 \%$ of the cases, the sciatic nerve division was observed in the popliteal fossa, $15.83 \%$ above it, and in $1.67 \%$ a high division occurred. In addition, in $98.3 \%$, the sciatic nerve was observed exiting below the piriformis muscle as a single trunk and in $1.67 \%$ higher divisions were observed

$89 \%$ presented normal anatomy of the sciatic nerve and its path. Two distinct variations were identified: in $8.8 \%$, the common fibular branch was observed passing through the piriformis and in $2.9 \%$ the common fibular branch passed over the piriformis

A typical anatomical pattern was found in $93.6 \%$. In $4.1 \%$, the common fibular nerve and the tibial nerve passed below a double piriformis. In $0.3 \%$, both nerves penetrated the piriformis. In $0.3 \%$ both nerves passed above the piriformis and $1.4 \%$ presented anatomical variations not classified

In $73.1 \%$ of the cases, the sciatic nerve followed its normal pattern. In $14.3 \%$ it was divided into its terminal branches above the piriformis. One branch going through the muscle, the other under it

An accessory muscle belly of the left piriformis was observed, and the common fibular branch passed between its fibers and the standard piriformis muscle

In $98 \%$ of cases, on both sides, the sciatic nerve passed below the piriformis muscle (normal pattern). And in the other $2 \%$ variant formations occurred, which could be related to piriformis syndrome

In $72.5 \%$ of the cases the normal anatomical pattern was verified (bilaterally 66\%). In $27.5 \%$, there was a high division of this nerve in the gluteal region. In addition, $96 \%$ of the nerve left the pelvis through the infrapiriform foramen, while in $4 \%$ variations of the sciatic nerve in relation to the piriformis muscle were detected

The normal anatomy patterns were found in $87 \%$ of cases.

The other $13 \%$ showed one of the divisions of the sciatic nerve passing through the piriformis, and the other division passing below that $72.5 \%$ of the analyzed sciatic nerves had a division at the popliteal fossa level; that is, the expected anatomical pattern corresponding to the type 1 anatomical variation. In the other $27.5 \%$ of cases, there was a high bifurcation of this nerve, in the posterolateral region or in the gluteal region, related to the type 5 variation $^{21}$. A retrospective study evaluating 755 MRI scans found that in $87 \%$ of cases the normal pattern of division was present. In $13 \%$ of the anatomical alterations, it was observed that one of the sciatic nerve divisions passed between the piriformis muscle fibers ${ }^{22}$. 



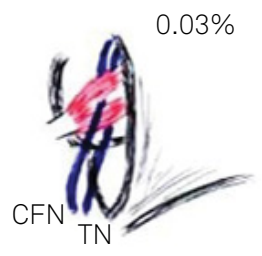

7

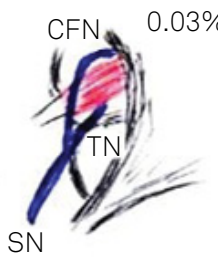

8
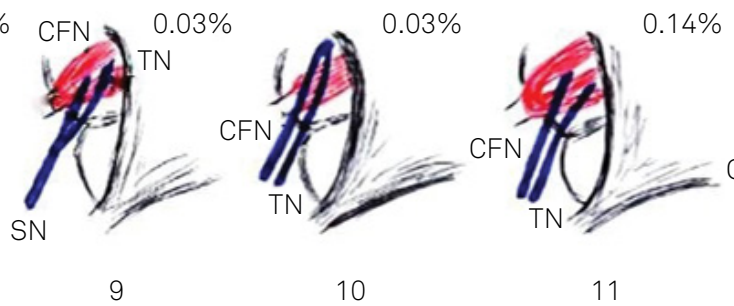



12

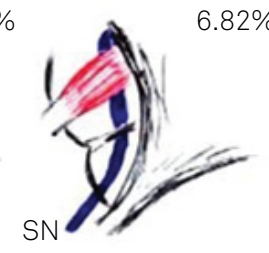

13

IO: Infrapiriform opening; SO: suprapiriform opening; PM: piriformis muscle; SSL: sacral spinal ligament; MSF: minor sciatic foramen; TSL: tuberal sacral ligament; SN: sciatic nerve; TN: tibial nerve; CFN: common fibular nerve; AT: abnormal trunk.

Figure 2. Schematic representations of the common form (1) and variants (2-13) found in the sciatic nerve anatomy in the studies selected for analysis.

Individuals with sciatic nerve anatomical division variation may have more than one type of variation when comparing the contralateral limb. This information is consistent with a cadaver study in which the right lower limb nerve passed beneath the piriformis muscle while in the lower left limb the fibular nerve passed inside its belly in the same individual ${ }^{14}$.

It is known from the literature that the common fibular, and tibial roots of the sciatic nerve have sensory and motor roles in the lower limbs. The former innervates the short head of the femoral biceps and controls the anterior muscle compartments of the leg and foot and lateral leg that is responsible for movements of ankle and toe extension and eversion of the foot, as well as contributing to the sensation of the anterior and lateral portions of the leg and foot. The tibial root is responsible for the innervation of the other posterior compartment muscles of the thigh, leg and posterior portion of the sole of the foot ${ }^{2}$.

In another study based on the analysis of cadaveric parts, we also found anatomical variations of the sciatic nerve. In three cases, the common fibular branch passed over the piriformis muscle and in another nine the common fibular nerve passed through this muscle fiber ${ }^{17}$.

According to Pećina ${ }^{24}$, in the type 3 variation, there is a greater probability of development of piriformis syndrome. Since the common fibular nerve passes through the piriformis muscle fibers, there will be compression of the nerve fiber in situations of hypertrophy, inflammation or even a normal contraction of this muscle. In this way, the individual may present with sensory, motor and neurological disorders, triggering characteristic symptoms of paresthesia and paresis in the cutaneous territories and motor compartments, which are the areas of competence of that nerve.

In this review, type 3 was the most common variant. We consider that in order to cause sciatica, the tense piriformis muscle compresses the nerve, or part of it, generating ischemia in its vasa nervorum, causing typical neuropathy $y^{3}$. Therefore, when compression occurs in the normal type 1 form, a clinical response compatible with paresthesias and paresis in the areas of competence of the sciatic nerve, classically called sciatica, is to be expected. But in every variation, it is possible to find a different effect. In these cases, type 3 variants, for example, there is a strong tendency for the fibular fiber to compress the common fibular root alone or even before compressing the tibial root, creating a whole clinical scenario, as the initial symptoms could be manifested as paresthesias and paresis in the territories of the areas of competence of the common fibular nerve in an isolated way and not in the areas of competence of the tibial nerve, which may confuse the clinical reasoning at the time of diagnosis. In this case, a sciatica would be reported in the lateral and anterior leg areas and foot alone.

On the other hand, Fishman et al. ${ }^{25}$, from the analysis of the H-reflex test, observed that the tibial nerve is more severely affected than the common fibular nerve in piriformis syndrome, although the anatomical variations in the path of the latter nerve are more rare. Thus, variations in the common fibular nerve would not necessarily be related to the piriformis syndrome.

In addition to the anatomical variations related to the level where the division of the sciatic nerve occurs, as well 
as its path to the respective innervation territory, other anatomical variations of the relationship of this nerve and the piriformis muscle have been reported. Polesello et al. ${ }^{19}$ identified an accessory muscle sheath in the left piriformis muscle. This variation increased the tension and compression in the sciatic nerve, generating a neuralgic picture, since the muscle tendon was transfixing the nerve.

Twelve variant forms have been observed in the sciatic nerve during its exit from the pelvis. It is known that compression of the sciatic nerve generates sciatica, characterized by paresthesias in the posterior thigh region, extending down the whole leg and foot, except for the medial regions, which are competence areas of the saphenous nerve originating from the femoral nerve. Additionally, it is also possible to observe paresis (force deficit) for joint movements of hip extension, knee flexion, ankle flexion and extension, as well as inversions and eversions.

The clinical picture may change when one of the sciatic nerve roots is selectively compressed during its passage through the larger sciatic foramen. When there is selective compression at the origin of the sciatic nerve tibial root, a clinical response is expected with paresthesias in the posterior thigh area, leg and possibly in the plantar area of the foot. It is also possible to find paresis in the articular movements of the muscles of the leg and posterior foot compartment muscles as well as in the plantar area - territories of sciatic nerve competence.

Therefore, it is believed that sciatica can be clinically demonstrated in various ways and it is up to the physician to recognize it.

In conclusion, in all the analyzed studies a higher prevalence of the normal anatomical pattern of the sciatic nerve was observed, which showed an occurrence higher than $70 \%$. The most frequent variations were those of type 3 , in which the common fibular nerve passes through the fibers of the piriformis muscle. This type of variation has been related to piriformis syndrome; however, it does not seem to be the only one, as other variations, even with a lower percentage of occurrence, were associated with this clinical condition. Other studies, especially in vivo, are necessary in order to study the relationship between the types of anatomical variation of the sciatic nerve, symptomatology and degree of impairment, and piriformis syndrome.

We believe that knowledge of the variant division forms of the sciatic nerve prior to its exit from the pelvis can help the physician understand the different clinical manifestations of sciatica, enabling a precise diagnosis and, consequently, more effective treatment.

\section{References}

1. Shailesh P, Mitesh S, Rakesh V, Ankeer Z. Rathod SP. A variation in the high division of the sciatic nerve and its relations with the piriformis muscle. Natl J Med Res. 2011;1(2):27-30.

2. Shewale AD, Karambelkar RR, Umarji BN. Study of the variations in the divisions, course and termination of the sciatic nerve.J Krishna Inst Med Sci Univ. 2013;2(1):62-8.

3. Vicente EJ, Viotto MJ, Barbosa CA, Vicente PC. Study on anatomical relationships and variations between the sciatic nerve and piriformis muscle. Rev Bras Fisioter. 2007;11(3):197-202. https://doi.org/10.1590/S1413-35552007000300009

4. Natsis K, Totlis T, Konstantinidis GA, Paraskevas G, Piagkou M, Koebke J. Anatomical variations between the sciatic nerve and the piriformis muscle: a contribution to surgical anatomy in piriformis syndrome. Surg Radiol Anat. 2014 Apr;36(3):273-80. https://doi.org/10.1007/s00276-013-1180-7

5. Santos CM, Pereira CU, Morais AA. Piriformis syndrome: a review of the literature.J Bras Neurocirurg. 2009;20(1):46-52.

6. Jankovic D, Peng P, van Zundert A. Brief review: piriformis syndrome: etiology, diagnosis, and management. Can J Anaesth. 2013 Oct;60(10):1003-12. https://doi.org/10.1007/s12630-013-0009-5

7. Cassidy L, Walters A, Bubb K, Shoja MM, Tubbs RS, Loukas M. Piriformis syndrome: implications of anatomical variations, diagnostic techniques, and treatment options. Surg Radiol Anat. 2012 Aug;34(6):479-86. https://doi.org/10.1007/s00276-012-0940-0

8. Machado FA, Babinski MA, Brazil FB, Favorito LA, Abidu-Figueiredo M, Costa MG. Anatomical variations between sciatic nerve and piriform muscle during fetal period in human. Int J Morphol. 2003;21(1):29-35. https://doi.org/10.4067/S0717-95022003000100005

9. Landis JR, Koch GG. The measurement of observer agreement for categorical data. Biometrics. 1977 Mar;33(1):159-74. https://doi.org/10.2307/2529310
10. Greenhalgh T. Assessing the methodological quality of published papers. BMJ. 1997 Aug;315(7103):305-8. https://doi.org/10.1136/bmj.315.7103.305

11. MacDermid JC, Walton DM, Avery S, Blanchard A, Etruw E, McAlpine C, et al. Measurement properties of the neck disability index: a systematic review.J Orthop Sports Phys Ther. 2009 May;39(5):400-17. https://doi.org/10.2519/jospt.2009.2930

12. Berihu BA, Debeb YG. Anatomical variation in bifurcation and trifurcations of sciatic nerve and its clinical implications: in selected university in Ethiopia. BMC Res Notes. 2015 Nov;8(633):633. https://doi.org/10.1186/s13104-015-1626-6

13. Carnevalli FU, Fagundes LE, Pelozo Junior O, Garbelotti Junior SA. [Piriformis syndrome and its topographical relationships].In: IX Encontro Latino Americano de Iniciação Cientifica, V Encontro Latino Americano de Pós-Graduação Universidade do Vale do Paraíva. [s.d.] [cited 2017 Sept 7]. Available from: http://www.inicepg.univap.br/cd/INIC_2005/epg/ EPG2/EPG2-9.pdf

14. Gomes BA, Ramos MR, Fiorelli RK, Almeida CR, Fiorelli SK. Topographic anatomical study of the sciatic nerve relationship to the posterior portal in hip arthroscopy. Rev Col Bras Cir. 2014;41 (6):440-4. https://doi.org/10.1590/0100-69912014006010

15. Jacomo AL, Martinez CA, Saleh SO, Andrade M, Akamatsu FE. Unusual relationship between the piriform muscle and sciatic, inferior gluteal and posterior femoral cutaneous nerves. Int J Morphol. 2014;32(2):432-4. https://doi.org/10.4067/S0717-95022014000200008

16. Kabacki AD, Buyukmumcu M, Yilmaz MT, Cicekcisabi AE, Akin D. Anatomical structure and topographic anatomy of sciatic nerve in human fetuses. J Anat Soc India. 2016;65(suppl 1):25-38. https://doi.org/10.1016/j.jasi.2015.12.001 
17. Lewis S, Jurak J, Lee C, Lewis R, Gest T. Anatomical variations of the sciatic nerve, in relation to the piriformis muscle. Translational Res Anat. 2016;5(1):15-9. https://doi.org/10.1016/j.tria.2016.11.001

18. Pokorný D, Jahoda D, Veigl D, Pinskerová V, Sosna A. Topographic variations of the relationship of the sciatic nerve and the piriformis muscle and its relevance to palsy after total hip arthroplasty. Surg Radiol Anat. 2006 Mar;28(1):88-91. https://doi.org/10.1007/s00276-005-0056-x

19. Polesello GC, Queiroz MC, Linhares JP, Amaral DT, Ono NK. Anatomical variation of piriformis muscle as a cause of deep gluteal pain: diagnosis using MR neurography and treatment. Rev Bras Ortop. 2013;48(1):114-7. https://doi.org/10.1016/j.rbo.2012.12.001.

20. Sulak O, Sakalli B, Ozguner G, Kastamoni Y. Anatomical relation between sciatic nerve and piriformis muscle and its bifurcation level during fetal period in human. Surg Radiol Anat. 2014 Apr;36(3):265-72. https://doi.org/10.1007/s00276-013-1179-0
21. Ugrenović S, Jovanović I, Krstić V, Stojanović V, Vasović L, Antić $\mathrm{S}$, et al. [The level of the sciatic nerve division and its relations to the piriform muscle]. Vojnosanit Pregl. 2005 Jan;62(1):45-9. https://doi.org/10.2298/VSP0501045U

22. Varenika V, Lutz AM, Beaulieu CF, Bucknor MD. Detection and prevalence of variant sciatic nerve anatomy in relation to the piriformis muscle on MRI. Skeletal Radiol. 2017 Jun;46(6):751-7. https://doi.org/10.1007/s00256-017-2597-6

23. Rodrigue T, Hardy RW. Diagnosis and treatment of piriformis syndrome. Neurosurg Clin N Am. 2001 Apr;12(2):311-9. https://doi.org/10.1016/\$1042-3680(18)30056-1

24. Pećina M. Contribution to the etiological explanation of the piriformis syndrome. Acta Anat (Basel). 1979;105(2):181-7. https://doi.org/10.1159/000145121

25. Fishman LM, Dombi GW, Michaelsen C, Ringel S, Rozbruch J, Rosner $\mathrm{B}$, et al. Piriformis syndrome: diagnosis, treatment, and outcome: a 10-year study. Arch Phys Med Rehabil. 2002 Mar;83(3):295-301. https://doi.org/10.1053/apmr.2002.30622 